\title{
CLINICAL AND RADIOGRAPHIC EVALUATION OF THE USE OF ANTERO-LATERAL WALL OF MAXILLARY SINUS FOR RECONSTRUCTION OF ORBITAL FLOOR DEFECT
}

\begin{abstract} which lead to a restriction in eye movement. from an intraoral donor site which minimizes its morbidity. reconstruction of orbital floor defects in ten patients. enophthalmos, limitation of eye movements and progressive infraorbital nerve hypoesthesia. postoperatively then once weekly for two weeks and then monthly for 3 months.

RESULTS: All patients with preoperative diplopia had significant improvement postoperatively. them showed improvement in the follow up visits. especially in cases of small to medium defects $(<3 \mathrm{~cm} 2)$.

KEYORDS: Anterolateral wall of maxilla, autogenous graft, orbital floor reconstruction, enophtalmos.

1-BDS, MS, Alexandria University, Faculty of Dentistry, Alexandria University.

2-Professor at Department of Oral and Maxillofacial Surgery, Faculty of Dentistry, Alexandria University.

3-Assistant Professor at Department of Oral and Maxillofacial Surgery, Faculty of Dentistry, Alexandria University.
\end{abstract}

Mohamed M. Aamer ${ }^{1} B D S$, Nagy E. Hassan² $P h D$, Hala R. Ragab ${ }^{3} P h D$.

INTRODUCTION: The orbital floor fracture results in disruption of bony continuity, enophtalmos, diplopia and herniation of orbital content

Auotogenous bone graft remains as the gold standard for reconstruction of orbital floor defects, the anterolateral wall of maxillary sinus is considered as one of the donor site used in the reconstruction of the orbital floor defects, which has many advantages such as biocompatibility, strength, vascularization and has no immune reaction. In addition, its contour fits exactly the orbital floor defect, a simple harvesting technique

OBJECTIVE: We aimed in the present study to evaluate the use of anterolateral wall of maxillary sinus clinically and radiographically in the

MATERIALS AND METHODS: All operated patients had more or less one or more signs and symptoms of orbital floor fracture as diplopia,

The graft harvested with peizosurgery from contralateral side of the fracture, the donor site is covered by a collagen membrane to prevent soft tissue infiltration. The harvested bone graft is adapted to the defect with no other means of fixation. The follow-up schedule was 3 days

8 patients out of 9 with preoperative ocular restriction had improvement in the postoperative follow up visits. 6 patients with preoperative enophthalmos showed improvement in the postoperative follow up visits. 7 patients with infra orbital nerve paresthesia preoperatively, all of

CONCLUSION: The study concluded that the anterolateral wall of the maxillary sinus is a suitable material for orbital floor reconstruction,

\section{INTRODUCTION}

Half of the fractures of the face and skull involve the mid face, and in these cases the orbital floor is regularly involved together with the zygomatic fractures, or as the sole fracture (blowout fracture) (1).

Depending on the mechanism that lead to the occurrence of the fracture ,the extent of fracture dislocation, the orbital tissue (including the eye muscles) can prolapse into the maxillary sinus, which results in enophthalmos and diplopia (2).

According to the literature, the orbital floor is extremely thin, it is the most frequently susceptible part to be fractured such fractures represent 67 to $84 \%$ of cases of orbital fractures $(3,4)$.

Orbital floor fractures can be broadly classified as pure or impure blowout fractures; the first are isolated orbital floor fractures, and the second are associated with an orbital rim fracture, involving other skeletal elements: zygomatic, frontal, nasoethmoidal, or maxillary bones (5).

The orbital complications which may result from these fractures : diplopia, restriction of ocular motility, enophthalmos, hypoglobus, and infraorbital dysesthesia (5).

So proper examination, diagnosis and treatment plan should be performed, improper treatment or misdiagnosis of orbital floor fractures may result in permanent diplopia, enophthalmos or nerve dysesthesia (3).

The goal of surgical repair of orbital fractures is to restore the traumatized wall in order to prevent herniation of the globe contents into the maxillary sinus, as it causes undesirable fat atrophy, disturbance in the ocular motility, many functional and esthetic problems (6).

Methods of orbital floor reconstruction have a great controversy among surgeons. The choice of material depends on the size and complexity of the orbital fracture. The ultimate goal of orbital floor repair is to restore function and form in the simple possible way(7).

In orbital floor fractures surgeon has the option of using either autogenous grafts or alloplastic materials .Autogenous grafts used in orbital floor defect reconstruction include calvarial, iliac bone, mandibular symphyseal, split rib, cartilage and antral wall graft. There are two main types of alloplastic materials: resorbable type such as Gelfilm, polygalactin film, and a variety of homografts and the non resorbable type which include Silastic sheets, Marlex mesh, Teflon, Prolene, polyethylene and metallic alloys (8).

The ideal reconstruction material for orbital floor or wall reconstruction should be easy to mold, easy to anchor, biocompatible, strong, readily available, restoring the orbital form and supporting the function (9).

Autogenous bone remains the standard by which all other grafting materials are measured, has many advantages : relative resistance to infection, incorporation into new bone, absence of a foreign body reaction, decreased incidence of extrusion (10).

Alloplastic materials such as metallic mesh, highdensity porous polyethylene silicone and also resorbable alloplasts such as polylactide and polydioxanone are widely used. The advantages of alloplasts include their availability and elimination of a second surgical donor site. However, 
these materials may elicit a foreign body reaction with or without extrusion (11).

The aim of the current study was to evaluate the feasibility of the anterolateral wall of the maxillary sinus as bone graft in the reconstruction of the orbital floor.

\section{MATERIALS AND METHODS}

A total of 10 patients were included in this study, they were admitted in the Oral and Maxillofacial surgery Department, Faculty of dentistry, Alexandria University suffered from orbital blowout fractures unilaterally or bilaterally, with an intact anterolateral wall of maxilla on the contralateral side indicated for surgical repair.

Patients suffered from bone diseases related to maxilla or from chronic maxillary sinusitis or had a fracture of anterolateral wall of the maxilla on the contralateral side were excluded from the study.

\section{Preoperative phase}

Patients were diagnosed by computed tomography (CT) and evaluated for the ocular globe trauma by an ophthalmologist. The indications for surgery included: diplopia more than 7 days, enophthalmos, hypoglobus, radiographically the defect was more than $50 \%$ of orbital floor, limitation in ocular mobility and progressive infraorbital hypoesthesia .

Clinical examination started by Systematic inspection of the zygomatico orbital area from different aspects (frontal, superior and inferior) for assessment of the following:

Alteration of ocular level (dystopia), enophthalmos after seven to ten days, deepening of supratarsal folds, narrowing of the palpebral fissure, development of diplopia especially upward gaze, restricted ocular movement and presence or absence of paresthesia through subjective evaluation of the patients.

During the preoperative period each patient received medications including; broad spectrum antibiotic Amoxicillin $875 \mathrm{mg}$ + Clavulanic acid $125 \mathrm{mg}$ tablets (Augmentin $1 \mathrm{gm}$ Glaxosmith Kline Beecham Pharmaceutical Co., Bentford, England) every 12 hours , and nonsteroidal anti-inflammatory analgesic diclofenac potassium $50 \mathrm{mg}$ tablets (Cataflam $50 \mathrm{mg}$ tablets, Novartis Pharma AG, Basle, Switzerland) every 8 hours .

\section{Operative phase}

The operation was performed under general anesthesia with intubation and strict aseptic conditions. The forced duction test was performed to confirm the entrapment of the inferior rectus muscle.

The orbital floor was first explored by a subtarsal incision to confirm the preoperative evaluation of the bony defect and herniation of the orbital contents.

Precise reduction of the maxillo-zygomatico-orbital segments was followed by rigid internal fixation with titanium miniplates for all fractured segments.

From the contralateral side bone graft was harvested carefully by aid of peizosurgery according to the size of orbital defect.

Periorbital tissue herniating in the maxillary sinus was disengaged from bony defect and the harvested graft was adapted to the orbital floor. No further securing to the bone graft (with screws or suture) was necessary. The forced duction test was done to ensure freeing of all herniated soft tissues.
Closure of the subtarsal incision was done in layers after achieving hemostasis. Collagen membrane was placed over the maxillary sinus Schneiderian membrane (donor site).

\section{Postoperative phase}

After the surgical procedure, each patient continued on the same regimen of antibiotics and analgesics for one week postoperatively to control infection and pain.

The patient was discharged 24 hours after surgery after being sure that he is completely free from any immediate postoperative complications including bleeding or retrobulbar hemorrhage.

Sutures were removed after 7 days.

The follow up schedule: 3 days postoperatively then once weekly for two weeks and then monthly for 3months.

The evaluated points were the ocular mobility, any signs or symptoms of maxillary sinusitis, enophthalmos and diplopia, all were compared with the preoperative status.

Postoperative CT was requested to evaluate the repair of orbital floor defect.

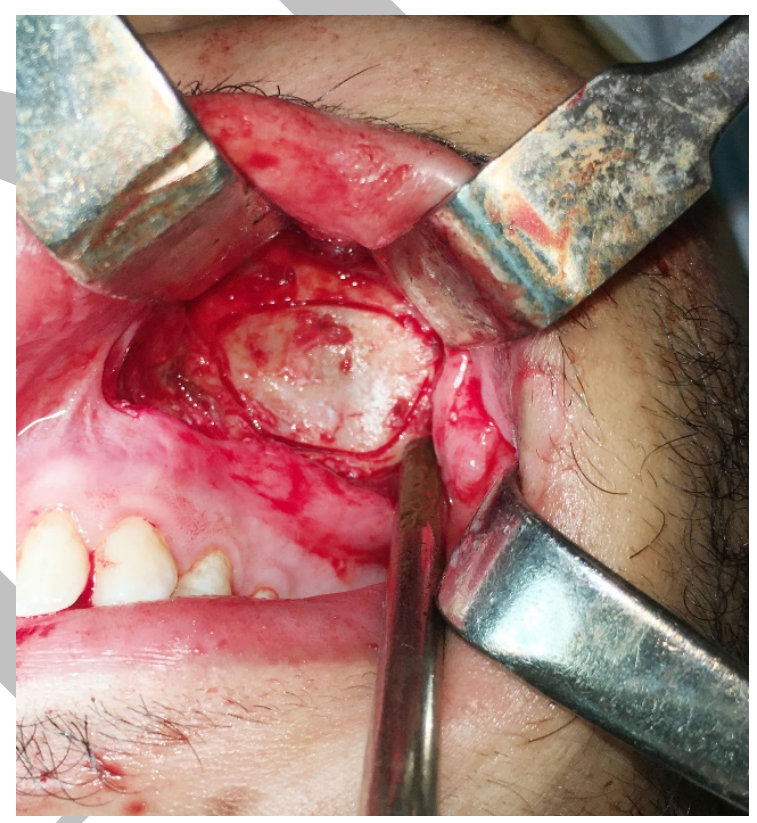

Figure (1): Bone graft from the donor site.

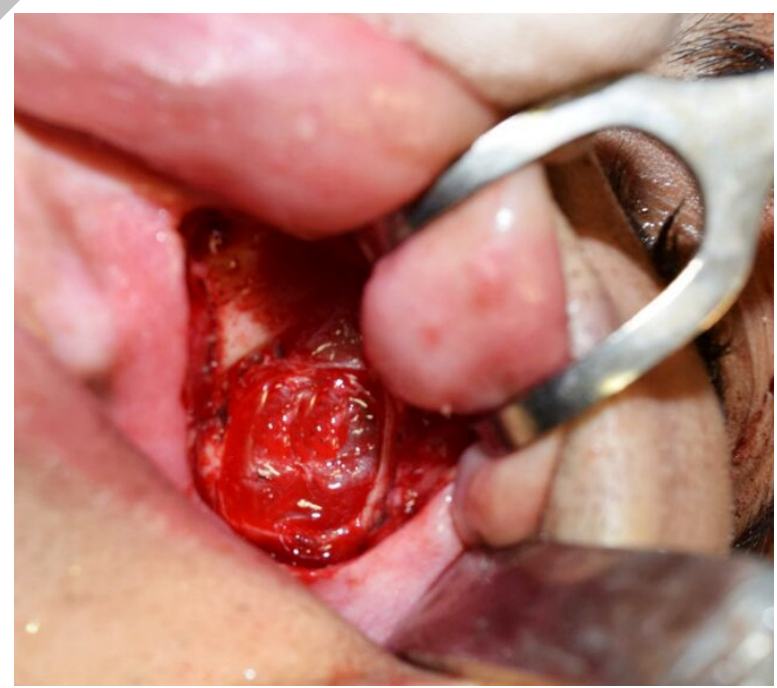

Figure (2): Sinus membrane intact. 


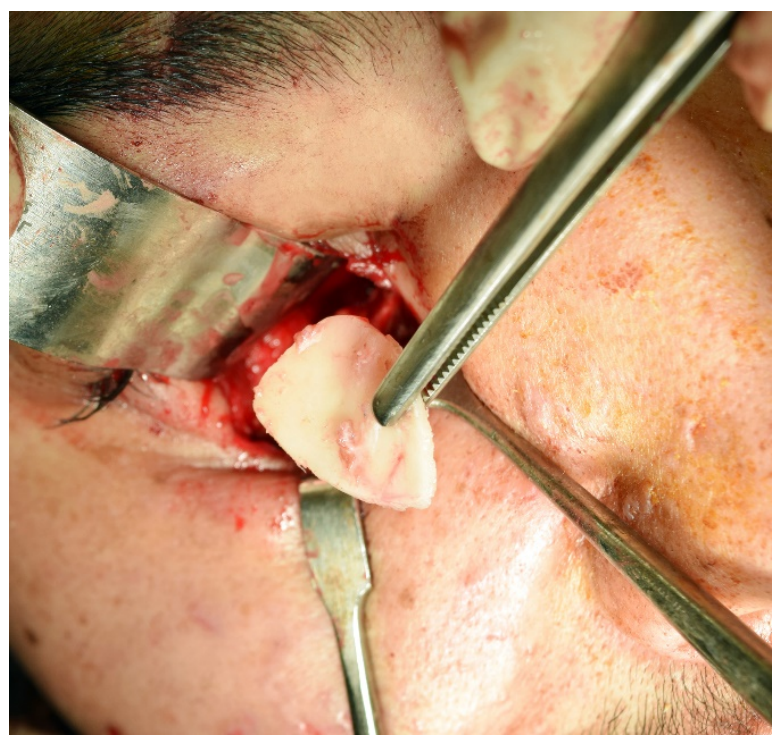

Figure (3): Insertion of the bone graft.

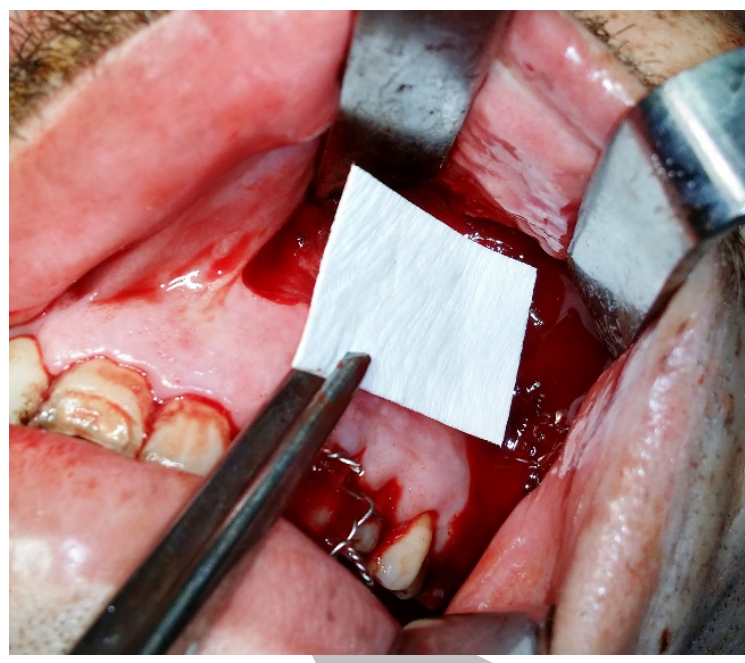

Figure (4): Collagen membrane at donor site.
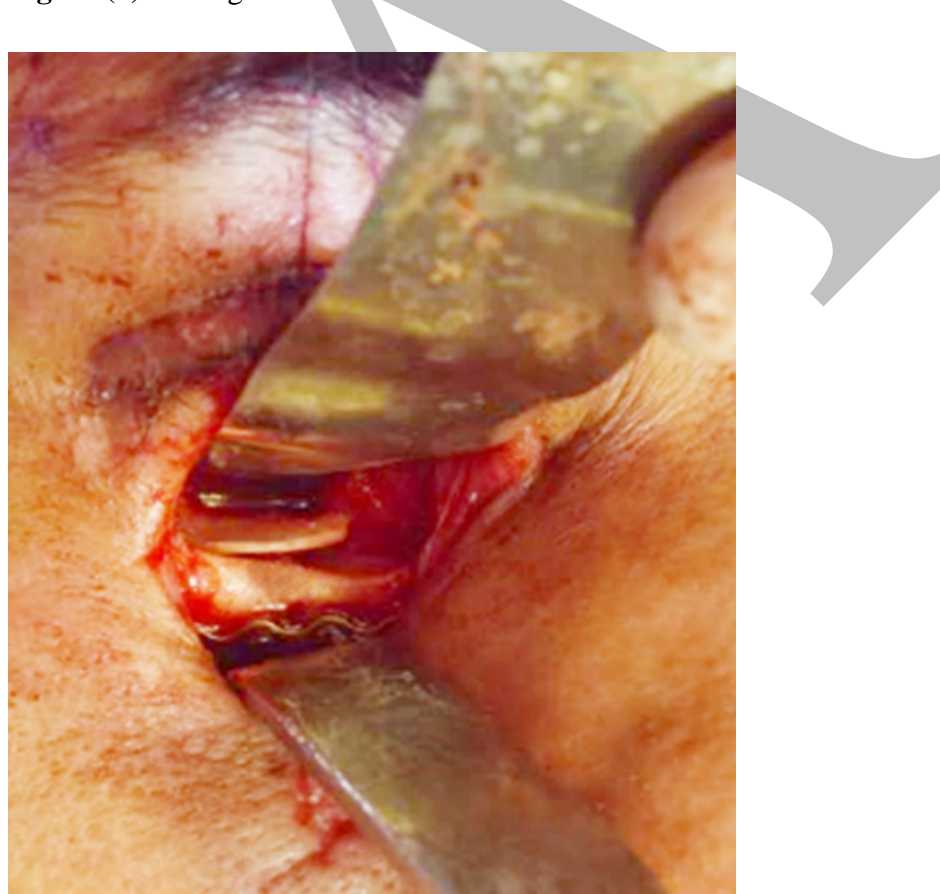

Figure (5): Graft in place.

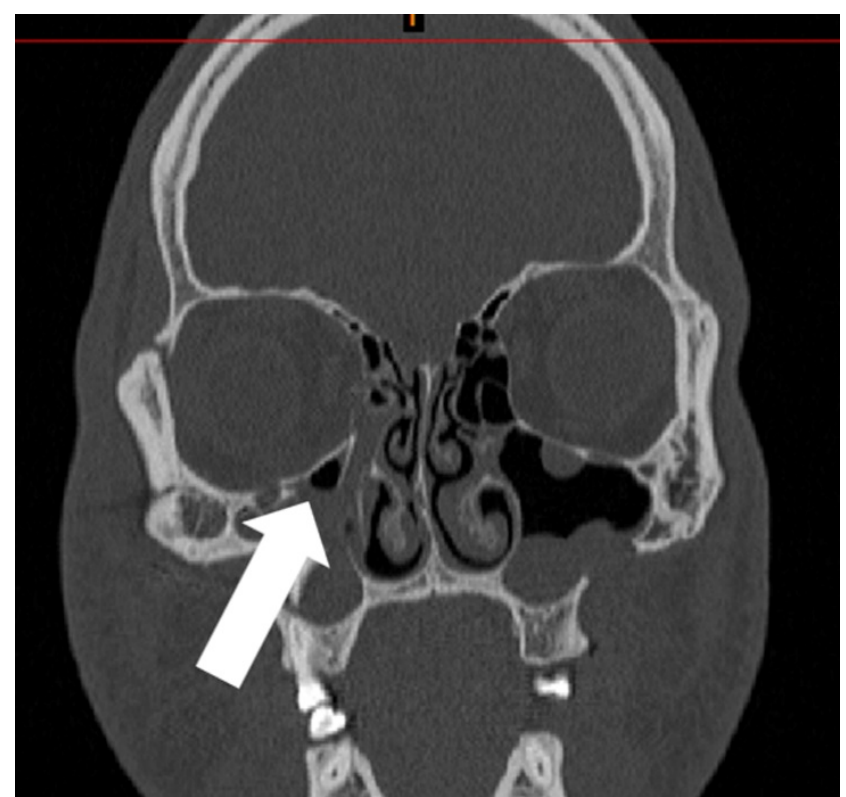

Figure (6): Postoperative CT (coronal cut) showing graft in place.

\section{RESULTS}

In the present study ten male patients, their ages ranged between 20-65 years with mean age of 42.5 years with orbital floor defect ranging from $2 \mathrm{~cm}^{2}$ to $3 \mathrm{~cm}^{2}$. The mechanism of trauma was Road traffic accident in 7 patients, personal assault in one patient and hit by hard object in two patients.

All patients had an orbital blowout fracture associated with zygomaticomaxillary complex fracture, there was one case associated with frontal, parietal, mandibular bone fractures and Lefort III fracture.

The surgical intervention of all patients was delayed, but kept it within 2 weeks from the trauma to allow time for clearing the initial edema and hemorrhage.

Diplopia was noted in 7 cases, limitation of ocular movements in upward gaze in 7 cases, limitation in all gazes in two patients, enophthalmos in 6 cases and Infraorbital nerve (ION) paresthesia was detected in 7 patients.

As patients with chronic maxillary sinusitis were excluded from this study, all the patients involved had no history of signs and symptoms of maxillary sinusitis and postoperatively All of them had slight tenderness and pain related to the donor site however, it is resolved within 10 days and no one complained from any signs or symptoms of sinusitis during follow up visits.

All the patients of preoperative diplopia showed significant improvement postoperatively, one of them complained of transient diplopia resolved after ten days.

8 patients out of 9 with preoperative ocular restriction showed improvement in the postoperative follow up visits.

6 patients out of 7 with preoperative enophthalmos showed improvement in postoperative follow up visits.

Infraorbital nerve parethesia was found preoperatively in 7 patients showed improvement in all cases postoperatively.

Only one patient had a sinus membrane tear which took place during graft elevation.

Although visual impairment was detected in two patients, complete resolution took place after 3 weeks.

Regarding the Post operative CT 8 patients out of 10 showed reconstruction of orbital defect in the anterior and posterior parts, one case showed posterior herniation of 
orbital content, so the patient had enophthalmos which wasn't improved, another patient had muscle and fat herniation so the restriction on upward gaze wasn't improved.

Complications such as infection, extrusion, implant migration, retrobulbar hemorrhage or ectropion did not occur in the current study.

Otherwise, all the patients enrolled in the current study were satisfied with the results of their surgery.

\section{DISCUSSION}

Treatment of traumatic orbital injuries in the damaged orbital wall reconstruction will continue to be a topic of considerable controversy. The ideal technique, which may involve different reconstructive materials and various surgical access sites, could be influenced by many factors, including characteristics of the maxillofacial trauma and the experience of the surgeons (12).

The present study was based on clinical recommendation evoked by Burnistine in 2002 (13) that recommended to delay the intervention ,but keep it within 2 weeks, as most patients with orbital floor fractures, a better clinical evaluation can be accomplished if time is allowed for clearing of the initial edema and hemorrhage.

Regarding the scar appearance and complication associated with the incisions, a Study was done by Santosh and Giraddi in 2011 (14) found that transconjunctival incision provides excellent exposure with a lower incidence of eyelid retraction and ectropion in comparison to subciliary and subtarsal incisions but needs more surgical skills.

Subtarsal incision used in the current study with no evidence of any ectropion and with an excellent unnoticeable scar within long follow up visits.

One of the most important advantage of the usage of the alloplastic material over the autogenous graft in orbital floor reconstruction is the availaibility of the alloplastic material in different sizes and shapes (15).

On the other hand, The antero-lateral wall of maxillary sinus has a limited size so the study was limited to cases with a small to medium orbital floor fracture defect (6) which couldn't be estimated directly from CT as its somehow depend on the reduction of ZMC fracture which will decrease the orbital floor defect size. Only in two cases the defect was larger than the harvested graft which appeared in post-operative CT.

Regarding the material selected, The basic objective of reconstruction of orbital defect is to restore orbital volume, function, and esthetics (16).

Very good clinical results have been reported by some surgeons, justifying the use of grafts from the anterior maxillary sinus wall primarily for pure blowout fractures $(12,17)$.

The main advantage of this technique is the adjacent locations of the injury and the operative field, facilitating the performance of open reduction and eliminating the need for further surgical interventions (17).

Further, we can manipulate from the site of the removed anterior maxillary sinus to reduce the herniated orbital contents, usually with a forefinger, and we can examine the condition of the reconstructed support through the anterior sinus (12).
The clinical usefulness of this technique was further confirmed by Copeland and Meisner in 1991(17) mainly for pure blowout fractures, while Cieślik et al in 2009 (18) also applied this bone grafting method to some cases of zygomaticoorbital fractures.

In cases of orbital floor fractures, especially those associated with complex fractures of the maxillo-zygomatic orbit, the anterior part of the maxillary sinus walls could be damaged $(19,20)$.

So, in the present study the graft harvested from the contralateral intact site by aid of piezosurgery in order to preserve the Schneiderian membrane .

We used the graft from contra lateral side in all cases, the graft size was determined after reduction of other fractures by using the template to make it more precise to the defect.

The use of antero-lateral wall of maxilla is an easy simple method for harvesting bone graft. The procedure is done intraorally without any extraoral scar which take place in harvesting other autogenous graft as iliac bone graft , calvarial and rib graft $(21,22)$. About $2 \times 3 \mathrm{~cm}$ of the graft can be harvested which is sufficient for smaller to moderate size defects.

One of the disadvantages of autogenous bone graft is the inability to adapt or reshape the graft to fit the orbital floor defect. In the present study, it was found that the contour of antero-lateral wall of maxilla exactly fits the anatomic contour of orbital floor defect (21).

According to the donor site morbidity, in this study as mentioned before ,the usage of anterolateral wall of maxilla from the intact contralateral side which is an intraoral site so the surgeon will be more aware of the anatomy of the field and less surgical time will be needed additionally the coverage of the donor site by collagen membrane after harvesting the graft will prevent soft tissue infiltration rather than bone formation (23). So less operative time less postoperative pain, and less morbidity are obtained.

Concerning handling of the graft, the graft was harvested after fixation of all other fractures and measuring by the template the size of the defect to be reconstructed (24).

Additionally, Kanno et al (12) fixed the harvested bone graft to the anterior lateral infraorbital rim with a bioresorbable plate however, in the present study no further screws or sutures were used.

Al-Dajani (25) found that a perforation of the Schneiderian membrane doubles the risk for the incidence of sinusitis or infection. Therefore, it is of great importance that any perforation should be avoided.

Stbinger et al (26) used the rose head bur to harvest the graft from the same side. In this study piezosurgery was used to harvest the graft which is another unique technique in order to preserve the Schneiderian membrane.

According to Baumann et al (27) a defect in the orbital floor (up to a size of $2.5 \mathrm{~cm}^{2}$ ) could be termed as small to moderate defects. In the current study postoperatively the defect measured in all cases ranging from $1-3 \mathrm{~cm}^{2}$ except in two cases the defects are more than $3 \mathrm{~cm}^{2}$. 
Table 1: Summary of Pre and postoperative findings.

\begin{tabular}{|c|c|c|c|c|c|}
\hline Patient & Age & Preoperative findings & $\begin{array}{l}\text { Postoperative } \\
\text { findings }\end{array}$ & CT findings & $\begin{array}{c}\text { Maxillary sinus } \\
\text { membrane } \\
\text { condition }\end{array}$ \\
\hline Case number 1 & $\begin{array}{c}35 \\
\text { years }\end{array}$ & $\begin{array}{l}\text { Diplopia, } \\
\text { restriction in upward gaze } \\
\text { ION paresthesia }\end{array}$ & $\begin{array}{l}\text { Improvement of all } \\
\text { the pre operative } \\
\text { findings }\end{array}$ & $\begin{array}{c}\text { Reconstructio } \\
n \text { was done }\end{array} \mid$ & Intact \\
\hline Case number 2 & $\begin{array}{c}33 \\
\text { years }\end{array}$ & $\begin{array}{c}\text { Diplopia } \\
\text { restriction of ocular movement } \\
\text { in(all gazes) } \\
\text { ION paresthesia }\end{array}$ & $\begin{array}{l}\text { Improvement of all } \\
\text { the pre operative } \\
\text { findings }\end{array}$ & $\begin{array}{c}\text { Reconstructio } \\
n \text { was done }\end{array} \mid$ & Intact \\
\hline Case number 3 & $\begin{array}{c}39 \\
\text { years }\end{array}$ & $\begin{array}{c}\text { Diplopia } \\
\text { restriction in upward gaze } \\
\text { enophthalmos }\end{array}$ & $\begin{array}{c}\text { Improvement of all } \\
\text { the pre operative } \\
\text { findings }\end{array}$ & $\begin{array}{c}\text { Reconstructio } \\
n \text { was done }\end{array} \mid$ & Intact \\
\hline Case number 4 & 20 years & $\begin{array}{c}\text { Diplopia } \\
\text { restriction in upward gaze } \\
\text { enophthalmos } \\
\text { ION paresthesia }\end{array}$ & $\begin{array}{c}\text { Improvement of all } \\
\text { the pre operative } \\
\text { findings except } \\
\text { enophtalmus }\end{array}$ & $\begin{array}{c}\text { Still posterior } \\
\text { herniation } \\
\text { exists }\end{array}$ & intact \\
\hline Case number 5 & 49 years & $\begin{array}{l}\text { Diplopia, } \\
\text { restriction in upward gaze } \\
\text { ION paresthesia }\end{array}$ & $\begin{array}{l}\text { Improvement of all } \\
\text { the pre operative } \\
\text { findings }\end{array}$ & $\begin{array}{c}\text { Reconstructio } \\
\text { n was done }\end{array}$ & Iatrogenic tear \\
\hline Case number 6 & 65years & $\begin{array}{l}\text { Restriction of ocular movement } \\
\text { in upward gaze }\end{array}$ & $\begin{array}{l}\text { Improvement of all } \\
\text { the pre operative } \\
\text { findings }\end{array}$ & $\begin{array}{c}\text { Reconstructio } \\
n \text { was done }\end{array} \mid$ & intact \\
\hline Case number 7 & & $\begin{array}{l}\text { Restriction of ocular movement } \\
\text { in upward gaze enophthalmos }\end{array}$ & $\begin{array}{l}\text { Improvement of all } \\
\text { the pre operative } \\
\text { findings }\end{array}$ & $\begin{array}{c}\text { Reconstructio } \\
n \text { was done }\end{array} \mid$ & intact \\
\hline Case number 8 & 27 & $\begin{array}{l}\text { Restriction of ocular movement } \\
\text { (all gazes) enophthalmos } \\
\text { ION paresthesia }\end{array}$ & $\begin{array}{c}\text { Improvement of all } \\
\text { the pre operative } \\
\text { findings }\end{array}$ & $\begin{array}{c}\text { Reconstructio } \\
n \text { was done }\end{array} \mid$ & intact \\
\hline Case number 9 & $\begin{array}{c}39 \\
\text { Years }\end{array}$ & $\begin{array}{c}\text { Diplopia } \\
\text { Restriction of ocular movement } \\
\text { in upward gaze } \\
\text { enophthalmos } \\
\text { ION paresthesia }\end{array}$ & $\begin{array}{l}\text { Improvement on all } \\
\text { except restriction }\end{array}$ & $\begin{array}{c}\text { In adequate } \\
\text { reconstructio } \\
n\end{array}$ & intact \\
\hline Case number 10 & $\begin{array}{c}51 \\
\text { Years }\end{array}$ & $\begin{array}{l}\text { Diplopia } \\
\text { enophthalmos } \\
\text { ION paresthesia }\end{array}$ & $\begin{array}{l}\text { Improvement of all } \\
\text { the pre operative } \\
\text { findings }\end{array}$ & $\begin{array}{c}\text { Reconstructio } \\
n \text { was done }\end{array} \mid$ & Intact \\
\hline
\end{tabular}




\section{CONCLUSION}

We concluded from this study that anterolateral wall of the maxillary sinus is a good option in the reconstruction of orbital floor defects smaller than $2.5 \mathrm{~cm}^{2}$, it is less invasive, less time consuming, and successful clinical results have been obtained, So this graft is suitable in the reconstruction of small and moderate size defects.

\section{CONFLICT OF INTEREST}

The authors declare that they have no conflicts of interest.

\section{REFERENCES}

1-Beck-Broichsitter BE, Acar C, Kandzia C, Jochens A, Wiltfang J, Becker ST. Reconstruction of the orbital floor with polydioxanone: A long-term clinical survey of up to 12 years. Br J Oral Maxillofac Surg.2015; 53: 736-40.

2-Wang S, Xiao J, Liu L, Lin Y, Li X, Tang W, et al. Orbital floor reconstruction: a retrospective study of 21 cases. Oral Surg Oral Med Oral Pathol Oral Radiol Endod.2008; 106 (3): 324-30.

3-Jank S, Schuchter B, Emshoff R, Strobl H, Koehler J, Nicasi A, et al. Clinical signs of orbital wall fractures as a function of anatomic location. Oral Surg Oral Med Oral Pathol Oral Radiol Endod. 2003; 96: 149-53.

4-Manolidis S, Weeks BH, Kirby M, Scarlett M, Hollier L. Classification and surgical management of orbital fractures: experience with 111 orbital reconstructions. J Craniofac Surg. 2002; 13: 726-37.

5-Tang DT, Lalonde JF, Lalonde DH. Delayed immediate surgery for orbital floor fractures: Less can be more. Can J Plast Surg. 2011; 19: 125-8.

6-Rai A, Datarkar A. Use of anteriolateral wall of maxilla for reconstruction of orbital floor fracture: A clinical study. Natl J Maxillofac Surg. 2013; 4: 173-6.

7-Avashia YJ, Sastry A, Fan KL, Mir HS, Thaller SR. Materials used for reconstruction after orbital floor fracture. J Craniofac Surg. 2012; 23: 1991-7.

8-Bande CR, Daware S, Lambade P, Patle B. Reconstruction of orbital floor fractures with autogenous bone graft application from anterior wall of maxillary sinus: A retrospective study. J Oral Maxillofac Surg. 2014; 14: 605-10.

9-Kontio R. Treatment of orbital fractures: the case for reconstruction with autogenous bone. J Oral Maxillofac Surg. 2004; 62: 863-8.

10-Potter JK, Malmquist M, Ellis E. Biomaterials for Reconstruction of the Internal Orbit. Oral Maxillofac Surg Clin North Am. 2012; 24: 609-27.

11-Ellis E, Messo E. Use of nonresorbable alloplastic implants for internal orbital reconstruction. J Oral Maxillofac Surg. 2004; 62: 873-81.
12-Kanno T, Sukegawa S, Takabatake K, Takahashi Y, Furuki Y. Orbital floor reconstruction in zygomatic-orbitalmaxillary fracture with a fractured maxillary sinus wall segment as useful bone graft material. J Oral Maxillofac Surgery Med Pathol. 2013; 25: 28-31.

13-Burnstine MA. Clinical recommendations for repair of isolated orbital floor fractures: An evidence-based analysis. Ophthalmology. 2002; 109: 1207-10.

14-Santosh BS, Giraddi G. Transconjunctival Preseptal Approach for Orbital Floor and Infraorbital Rim Fracture. J Maxillofac Oral Surg. 2011; 10(4):301-5.

15-Baino F. Biomaterials and implants for orbital floor repair. Acta Biomater. 2011; 7: 3248-66.

16-Cole P, Boyd V, Banerji S, Hollier LHJ. Comprehensive management of orbital fractures. Plast Reconstr Surg. 2007; 120: 57S-63S

17-Copeland M, Meisner J. Maxillary antral bone grafts for repair of orbital fractures. J Craniofac Surg. 1991; 2: 18-21.

18-Cieślik T, Skowronek J, Cieślik M, Cieślik-Bielecka A. Bone graft application from anterior sinus maxillary wall in orbital floor reconstruction. J Craniofac Surg. 2009; 20: 512-5.

19-Mandel MA. Orbital floor "blowout" fractures. Reconstruction using autogenous maxillary wall bone grafts. Am J Surg. 1975; 130: 590-5.

20-Ellis E, Tan Y. Assessment of internal orbital reconstructions for pure blowout fractures: Cranial bone grafts versus titanium mesh. J Oral Maxillofac Surg. 2003; 61: 442-53.

21-Movahed R, Pinto LP, Morales-Ryan C, Allen WR, Wolford LM. Application of cranial bone grafts for reconstruction of maxillofacial deformities. Proc (Bayl Univ Med Cent). 2013; 26: 252-5.

22-Garg V, Giraddi GB, Roy S. Comparison of efficacy of mandible and iliac bone as autogenous bone graft for orbital floor reconstruction. J Maxillofac Oral Surg. 2015; 14: 2918.

23-Bozzuto G, Ruggieri P, Molinari A. Molecular aspects of tumor cell migration and invasion. Ann Ist Super Sanita. 2010; 46: 66-80.

24-Iatrou I, Theologie-Lygidakis N, Angelopoulos A. Use of membrane and bone grafts in the reconstruction of orbital fractures. Oral Surg Oral Med Oral Pathol Oral Radiol Endod. 2001; 91: 281-6.

25-Al-Dajani M. Recent Trends in Sinus Lift Surgery and Their Clinical Implications. Clin Implant Dent Relat Res. 2016; 18: 204-12.

26-Stbinger S, Stricker A, Berg BI. Piezosurgery in implant dentistry. Clin Cosmet Investig Dent. 2015; 7: 115-24.

27-Baumann A, Burggasser G, Gauss N, Ewers R. Orbital floor reconstruction with an alloplastic resorbable polydioxanone sheet. Int J Oral Maxillofac Surg. 2002; 31: 367-73. 